dications for the various regimens available for the treatment of tumours of the head and neck. Until this evidence is available inappropriate management will continue to be given in some cases. A patient's first treatment is vital and dictates the whole prognosis of his disease, but at present this is selected by the clinician who first examines him and who, lacking data from controlled trials, usually chooses the treatment with which he is most familiar.

Fast neutrons are at present the subject of such a controlled clinical trial, and consultant radiotherapists and aural surgeons in London, Birmingham, and south-east England are collaborating. The early results of this trial will be the subject of a separate paper.

\section{References}

Catterall, et al. (1971). British fournal of Radiology, 44, 603.

Field, S. B. (1969). Radiology, 92, 381.

Field, S. B., Jones, T., and Thomlinson, R. H. (1968). British fournal of Radiology, 41, 597

Gray, L. H., et al. (1940). British fournal of Radiology, 13, 371.

Gray, L. H., et al. (1953). British fournal of Radiology, 26, 638

Gray, L. He and Read. J (1942). Britsh Yournal

Gray, I. H., and Read, J. (1942). British Fournal

Gray, L. H., and Read, J. (1944). British fournal of Radiology, 17, 271

Mitchell, J. S., (1946). Personal communication.

Morgan, R. L., and Morrison, R. M. (1969). Personal communication.

Sheline, G. E., et al. (1971). American fournal of Radiology, 111, 31.

Stone, R. S. (1944). Medical Physics, ed. O. Glasser, p. 816.

Stone, R. S. (1948). American fournal of Roentgenology, 59, 771.

Stone, R. S., and Larkin, J. C. (1942). Radiology, 39, 608.

Thomlinson, R. H. (1968). Frontiers of Radiation Therapy and Oncology, 3 , 109.

\title{
Effect of Prolonged Thiazide Treatment on Renal Lithium Clearance
}

\author{
V. PETERSEN, S. HVIDT, K. THOMSEN, M. SCHOU
}

British Medical fournal, 1974, 3, 143-145

\section{Summary \\ Renal lithium clearances were determined after the administration of a small test dose of lithium carbonate in 22 patients when they were on long-term treatment with thiazides and when they were not on such treatment. Thiazide administration led to a $24 \%$ reduction in the lithium clearance. Diuretic drugs should be used with caution in patients given lithium treatment, and lithium should be used with caution in patients receiving diu- retic treatment.}

\section{Introduction}

Lithium salts are used for the treatment and prophyiaxis of recurrent manic-depressive disorders (Schou, 1968). During lithium administration the serum levels of lithium must be maintained within a relatively narrow range: low levels lack effect and high levels are associated with a risk of side effects or intoxication. Lithium is excreted almost exclusively through the kidneys and the serum lithium level is therefore determined by the maintenance dosage and the renal elimination of lithium. Drugs and procedures which alter the renal lithium clearance are potentially dangerous to patients on lithium treatment. Among such drugs may be the diuretics.

In Denmark $11 \%$ of the population over 50 years of age take diuretics regularly (Skovbo et al., 1972). Diuretic drugs may be prescribed to manic-depressive patients on lithium treatment if they develop hypertension or oedema; lithium treatment itself occasionally leads to oedema formation (Demers and Heninger, 1970). Diuretics may also be prescribed for the treat-

\footnotetext{
Department of Internal Medicine, Thisted Centralsygehus, Thisted, Denmark

V. PETERSEN, M.D., Senior Registrar

S. HVIDT, M.D., Medical Superintendent

Psychopharmacology Research Unit, Aarhus University Psychiatric Institute, Risskov, Denmark

K. THOMSEN, PH.D., Research Associate

M. SCHOU, M.D., Professor of Biological Psychiatry and Research Director
}

ment of lithium-induced obesity (British Medical fournal, 1974).

The effect of diuretic drugs on the renal lithium clearance has been examined in healthy human subjects and rats. Single doses of frusemide, bendrofluazide, and ethacrynic acid given to the human subjects failed to affect the lithium clearance significantly (Thomsen and Schou, 1968). Daily administration of hydrochlorothiazide to rats over two to four weeks led to a reduction of the lithium clearance by $30-35 \%$ (Thomsen and Schou, 1973).

We have examined whether the renal lithium clearance is influenced by long-term administration of thiazides given in ordinary therapeutic doses to patients.

\section{Patients and Methods}

Altogether 22 patients ( 8 men and 14 women) were studied. They were admitted to the department of internal medicine at Thisted Centralsygehus during February to September 1973. All had oedema from various causes for which prolonged thiazide treatment was indicated.

Determinations of lithium clearance (after the administration of a small test dose of lithium carbonate), creatinine clearance, and urinary sodium excretion were carried out twice at intervals of about two months during and before or after treatment with thiazides. The thiazides used were hydroflumethiazide (Rontyl) and bendrofluazide (Centyl). Hydroflumethiazide was given in a dosage of $25 \mathrm{mg}$ daily together with $3.4 \mathrm{~g}$ of potassium chloride; the bendrofluazide dosage was $2.5 \mathrm{mg}$ daily. Clearance determinations during thiazide treatment were carried out after treatment periods of two months or longer, determinations after the discontinuance of thiazides being carried out when the patients had been without treatment for two months.

The patients had ordinary hospital food except on the days of examination, when they avoided caffeine-containing food, drinks, and drugs.

The examination procedure was as follows. At 9 p.m. the patients emptied their bladder, the urine sample being discarded. They then took $600 \mathrm{mg}$ of lithium carbonate by mouth; this corresponds to $16.2 \mathrm{mmol}$ of lithium. During the next 11 hours urine was collected for determination of the night creatinine clearance. At 8 a.m. a blood sample was drawn for determination of the serum lithium and creatinine concentrations. 
During the next seven hours urine was again collected for determination of the lithium clearance, the day creatinine clearance, and the urinary sodium excretion. At 3 p.m. a second blood sample was drawn for determination of the serum lithium and creatinine concentrations. The whole procedure was then repeated during the next 24 hours, starting at 9 p.m.

Lithium concentrations in the serum and urine were determined by flame photometry according to the methods of Amdisen (1967, 1971). Determinations were carried out in duplicate; relative standard deviations were about $1 \%$. Lithium clearances were calculated as described by Thomsen and Schou (1968). Sodium concentrations in the urine were determined by flame photometry. Creatinine concentrations in the serum and urine were determined with the alkaline picrate method.

In some instances the creatinine clearance showed such wide variation between day and night or between two consecutive days that incomplete emptying of the bladder was suspected. Such values were excluded from the study; exclusion was decided by a person who did not know whether the patient was on thiazide treatment at the time of examination.

\section{Results}

Renal lithium clearances of the patients during and before or after treatment with thiazides are shown in table I. For the group as a whole the mean lithium clearance decreased significantly from 20.2 to $15.4 \mathrm{ml} / \mathrm{min}$ during thiazide treatment, a fall of $24 \%$. For the 12 patients with paired observations the mean lithium clearance decreased from 19.8 to $15.7 \mathrm{ml} / \mathrm{min}-$ that is, $21 \%$. This failed to reach statistical significance. TABLE I-Renal Lithium Clearances of Patients during and before or after
Treatment with Thiazides. Figures in Italics are Means of Determinations on Treatment with Thiazides
Troo Consecutive Days

\begin{tabular}{c|c|c}
\hline \multirow{2}{*}{ Case No. } & \multicolumn{2}{|c}{ Lithium Clearance (ml/min) } \\
\cline { 2 - 3 } & Not on Treatment & During Treatment \\
\hline 1 & 15 & 19 \\
2 & 28 & 11 \\
3 & 35 & 17 \\
4 & 14 & 13 \\
5 & 18 & 16 \\
6 & 19 & 7 \\
7 & $12^{*}$ & 17 \\
8 & $16 *$ & 26 \\
9 & $20^{*}$ & 13 \\
10 & $27 *$ & 12 \\
11 & 20 & $\dagger$ \\
13 & 22 & \\
14 & 84 & \\
15 & 18 & 14 \\
16 & 28 & 19 \\
18 & 25 & 13 \\
19 & $\dagger$ & 13 \\
20 & & $15 \cdot 4 \ddagger$ \\
21 & & \\
22 & & \\
\hline Mean & & \\
\hline
\end{tabular}

* Determined after discontinuance of thiazide treatment. In the remaining patients clearances were determined before thiazide treatment was started. tQuantitative urine collection failed

$\ddagger$ Mann-Whitney U test, two-tailed $P<0.05$.

It had previously been shown that the renal lithium clearance is correlated with the creatinine clearance and with the urinary excretion of sodium (Thomsen and Schou, 1968; Thomsen et al., 1969; Geisler et al., 1971). We therefore examined whether the fall in the lithium clearance during thiazide treatment could be accounted for by a change in one of these variables.

The mean creatinine clearance was essentially the same whether the patients were on thiazide treatment $(78 \mathrm{ml} / \mathrm{min})$ or not $(84 \mathrm{ml} / \mathrm{min})$. The mean urinary sodium excretion was somewhat higher during thiazide treatment $(147 \mu \mathrm{mol} / \mathrm{min})$ than before or after treatment $(121 \mu \mathrm{umol} / \mathrm{min})$. The lithium clearances are plotted in the chart against urinary sodium excretions.

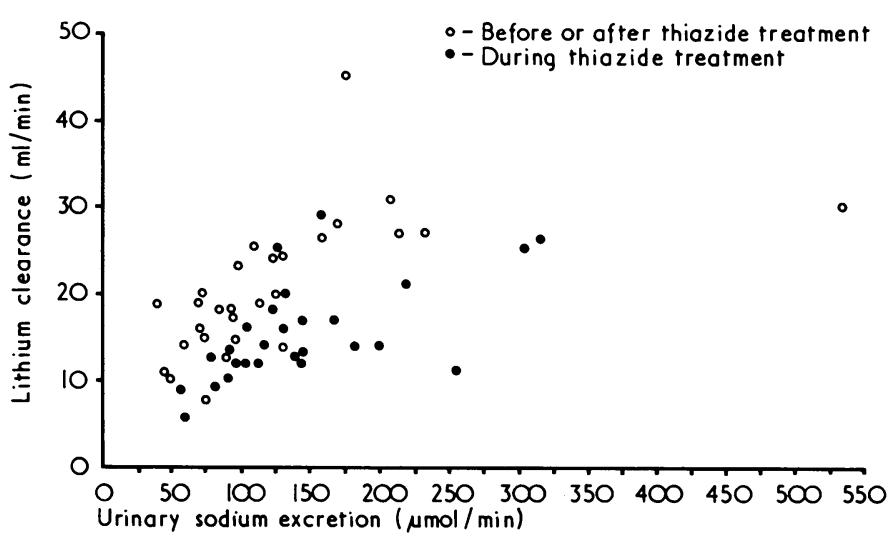

Renal lithium clearances plotted against urinary sodium excretions of patients during and before or after treatment with thiazide.

All the values are shown, so that some patients are represented by more than one point. The lithium clearance rose when the sodium excretion rose, both when thiazides were being given and before or after treatment. Thiazide treatment reduced the lithium clearance at all levels of sodium excretion.

The magnitude of the reduction is shown in table II at three levels of sodium excretion. The falls produced by thiazide treatment amounted to $47 \%, 26 \%$, and $35 \%$, respectively, in the groups of low, medium, and high sodium excretion. The falls were statistically significant in the two latter groups. The fall in the renal lithium clearance seen during thiazide treatment accordingly cannot be accounted for by the changes in creatinine clearance or urinary sodium excretion but must be a result of the thiazide treatment.

TABLE II-Renal Lithium Clearances of Patients during and before or after Treatment with Thiazides. Clearances are shown at Different Levels of Urinary Sodium Excretion

\begin{tabular}{|c|c|c|c|c|}
\hline \multirow{2}{*}{\multicolumn{2}{|c|}{$\begin{array}{l}\text { Urinary Sodium } \\
\text { Excretion } \\
(\mu \mathrm{mol} / \mathrm{min})\end{array}$}} & \multicolumn{2}{|c|}{$\begin{array}{c}\text { Mean Lithium Clearance (ml/min) } \\
\text { (No. of Determinations) }\end{array}$} & \multirow[b]{2}{*}{ Significance* } \\
\hline & & Not on Treatment & During Treatment & \\
\hline $\begin{array}{l}\text { Below } 75 \\
75-150 \text {. } \\
\text { Above } 150\end{array}$ & $\begin{array}{l}\cdots \\
\cdots\end{array}$ & $\begin{array}{l}15(\mathrm{n}=9) \\
19(\mathrm{n}=12) \\
31(\mathrm{n}=7)\end{array}$ & $\begin{array}{r}8(n=2) \\
14(n=17) \\
20(n=8)\end{array}$ & $\begin{array}{l}\text { N.S. } \\
\mathbf{P}<0.01 \\
\mathbf{P}<0.01\end{array}$ \\
\hline
\end{tabular}

- Mann-Whitney U test, two-tailed.

Mann-Whitney $U$ tes
N.S. = Not significant.

\section{Discussion}

The studies on patients produced the same results as the studies on rats, prolonged thiazide treatment leading to a fall in the renal lithium clearance. The fall was of the same order of magnitude in the two studies.

The following mechanism may underlie this phenomenon. Initially during thiazide treatment sodium excretion exceeds sodium intake, but this does not continue. After some days sodium excretion again equals sodium intake; this is due to a compensatory increase of sodium reabsorption in the proximal tubules. Lithium is reabsorbed with sodium in the proximal tubules (Thomsen and Schou, 1968), where thiazides exert little or no effect. Lithium is reabsorbed little or not at all in the more distal parts of the nephron (Thomsen and Schou, 1968), where thiazides have their main action. Long-term thiazide treatment may therefore lead to an increase in the reabsorption of lithium and a consequent decrease in the lithium clearance even under circumstances where sodium excretion is unaltered:

A reduction of the lithium clearance by $24 \%$ may well result in a rise of the serum lithium concentration to levels associated with side effects or a risk of intoxication. Thiazides, and pre- 
sumably also other diuretics, should therefore be used with caution in patients given lithium treatment, and long-term use should be accompanied by frequent determinations of the serum lithium concentration. If this increases, the lithium dosage should be reduced or treatment with diuretic drugs discontinued.

\section{References}

Amdisen, A. (1967). Scandinavian fournal of Clinical and Laboratory Investigation, $20,104$.
Amdisen, A. (1971). In Advances in Neuro-Psychopharmacology, ed. O. Vinar, Z. Votava, and P. B. Bradley, p. 67. Amsterdam, North-Holland Publishing.

British Medical fournal, 1974, 1, 168.

Demers, R., and Heninger, G. (1970). Fournal of the American Medical Association, 214, 1845.

Geisler, A., Schou, M., and Thomsen, K. (1971). Pharmakopsychiatrie. Neuro-Psychopharmakologie, 4, 149.

Schou, M. (1968). Fournal of Psychiatric Research, 6, 67.

Skovbo, P., et al. (1972). Ugeskrift for Laeger, 134, 165.

Thomsen, K., and Schou, M. (1968). American fournal of Physiology, 215,

823.
Thomsen, K., and Schou, M. (1973). Pharmakopsychiatrie. Neuro-Psychopharmakologie, 6, 264

Thomsen, K., et al. (1969). Pflügers Archiv für die gesamte Physiologie des Menschen und der Tiere, 308, 180.

\section{Circulating Antinuclear Antibody and Rheumatoid Factor in Coal Pneumoconiosis}

\section{A. SOUTAR, MARGARET TURNER-WARWICK, W. RAYMOND PARKES}

British Medical fournal, 1974, 3, 145-152

\section{Summary}

Circulating antinuclear antibody and rheumatoid factor have been measured in 109 coal miners with pneumoconiosis whose chest radiograph showed a range of abnormalities varying from simple pneumoconiosis of mild degree to advanced progressive massive fibrosis.

At a screening dilution of $1 / 10$ the overall incidence of antinuclear antibody was $17 \%$. In almost half of the positive cases the titre was $1 / 40$ or greater.

The prevalence of antinuclear antibody was lowest in those with simple pneumoconiosis $(9 \%)$ and highest in those with category $C$ progressive massive fibrosis $(27 \%)$. A similar but less striking trend was seen with rheumatoid factor, ranging from $6 \%$ in simple pneumoconiosis to $18 \%$ in category $C$ progressive massive fibrosis. The trend of increasing frequency of autoantibodies with advancing radiographic category was most marked when the frequencies of antinuclear antibody and rheumatoid factor were combined. These autoantibodies were found in $13 \%$ of the miners with simple pneumoconiosis and $45 \%$ of those with category $C$ progressive massive fibrosis $(P$ for the trend $=0.01$ ).

\section{Introduction}

The association between distinctive nodular types of radiographic opacities in the lungs of coal miners and rheumatoid arthritis was described by Caplan (1953) and confirmed in an epidemiological study by Miall et al. (1953). Later a similar radiographic appearance was described in miners without arthritis but in whom circulating rheumatoid factor (R.F.) was present (Caplan et al., 1962). These workers also found a slightly increased incidence of rheumatoid factor among miners with conventional progressive massive fibrosis and this was confirmed by Wagner and McCormick (1967).

Cardiothoracic Institute, London SW3 6HP and Pneumoconiosis Medical Panel, London N.W.1

C. A. SOUTAR, M.B., M.R.C.P., Lecturer, Department of Medicine

MARGARET TURNER-W.P.W ICK, D.M., F.R.C.P., Professor of Medicine MARGARET TURNER-WARWICK, D.M., F.R.C.P.
W. RAYMOND PARKES, M.D., M.R.C.P., D.P.H.
An increased incidence of rheumatoid factor has also been described in asbestos workers with pulmonary fibrosis (Pernis et al., 1965; Turner-Warwick and Parkes, 1970). TurnerWarwick and Parkes (1970) also found an increased incidence of antinuclear antibodies (A.N.A.) in asbestosis similar to that found in cryptogenic fibrosing alveolitis (Turner-Warwick and Doniach, 1965; Turner-Warwick and Haslam, 1971).

In view of the range of radiographic abnormalities seen in coal miners, some relating to the deposition alone of coal and other mineral dust and others associated with fibrosis of the lungs, we wished to establish whether antinuclear antibody could also be found in coal miners with pneumoconiosis and if so whether it related to certain types of radiographic abnormality.

\section{Patients and Methods}

The 109 subjects (miners and ex-miners) attended the London Pneumoconiosis Medical Panel during 1971 and 1972. They were admitted to the study consecutively and without selection provided that permission to take a blood sample was given. As about equal numbers of patients were required in each radiographic category of pneumoconiosis intake was stopped as sufficient numbers in each category were obtained. For this purpose the category was judged by one of us (W.R.P.) on a preliminary reading. No patient was selected or excluded on the basis of rheumatoid arthritis or any other clinical feature. All had been accepted by the Panel as having coal pneumoconiosis.

Recording of Clinical Data.-Clinical data and the history of coal dust exposure were recorded on a standard questionnaire when the patient attended the Panel. Most of the patients had worked in mines in more than one geographical area, so that the type of coal dust exposure was mixed.

Serological Tests.-Clotted blood samples were sent from the Pneumoconiosis Medical Panel to the laboratory. Antinuclear antibody was estimated by a standard double-layer immunofluorescent technique on sections of rat liver at a screening dilution of $1 / 10$. Titres of positive sera were estimated by serial serum dilutions using the same technique. Rheumatoid factor was estimated by the differential agglutination test (D.A.T.) (Rose et al., 1948) and by the agglutination of latex particles coated with human gammaglobulin (Behringwerke). A D.A.T. titre of $1 / 32$ or over was accepted as positive irrespective of the result of the latex test. A D.A.T. titre of $1 / 16$ was accepted as positive only if the latex test result was positive. Positive latex test results with a negative D.A.T. result were disregarded. 